\title{
Multi period pricing for managing local fruit supply chain
}

\author{
Erwin Widodo*, Rahaditya Dimas Prihadianto, and Dody Hartanto \\ Institut Teknologi Sepuluh Nopember, Industrial Engineering Department, Sukolilo, Surabaya, Indonesia
}

\begin{abstract}
Recently fresh fruit sector is grown not only due to increasing of demand that spirited by healthy lifestyle but also requirement of quality food should be eaten daily. Its complexity make many research considered fruit in certain supply chain, called as Fruit Supply Chain (FSC). In FSC, customers tend to purchase products with a longer remaining lifetime and avoid the ones which give aging signal. Customer willingness to pay decreases once the product start to be deteriorated, which may cause slower demand for aging fruits. Consequently, retailers should enable discounted price for aging fruits products to retain or improve demand rate. Main purpose of this research is explaining how to maximize supply chain profit by applying dynamic pricing. A set of mathematical model is optimized on this research. It addresses dynamic pricing for FSC players to achieve better profitability. The result proves that dynamic pricing is urgent to be done which is signaled by increment of FSC Profit. FSC players can separate selling period into three periods, which are forward buying period, normal price period, and markdown price period as implementation of this scheme.
\end{abstract}

\section{Introduction}

According to Soto-silva et al. [1], recently, fresh fruit sector is grown not only due to increasing of demand that spirited by healthy lifestyle but also requirement of quality food should be eaten daily. Based on FAO [2], fresh fruit is defined as portion of a plant housing seeds commonly eaten as dessert. Based on that definition, fresh fruit is considered as fruit which can be consumed raw. Repeatedly, Soto-silva et al. [1] argued that many regulation of food safety industrialization make fresh fruit should be produced by adopting good agricultural practices, automatization of sorting, selecting and packaging including sometimes some minor minimal processing tasks. Besides regulation, other factors such as globalization, competitor and customized products, make fresh fruits sector tends to be specialized and integrated vertically to become more competitive and dynamics. In this way, organizing fresh fruit under various related circumstances later called as Fruit Supply Chain (FSC).

Managing FSC is not as elementary as thought. Production fluctuation is one of challenge in fruit supply chain management. The fluctuation of agri-product, including fruits, its demand can be affected by several uncertain factors, such as weather, temperature, and customer preferences [3]. Fruit quality, like color, outlook appearance, and also best-before date label, become consideration aspects for customer to buy. Customer willingness to pay decreases once the product life is approached which may cause slower demand for aging fruits. Consequently, retailers should enable discounted price for aging fruits products to retain or improve demand rate. This research propose dymaic pricing model that accomoodate discounted price, normal price, and forward buying price as well. This model is extensive approach from preliminary research done by Maiti \& Giri [4] that presents two period pricing on short life cycle product and research from Fauza \& \& Lee [5] that presents revenue-based with $\mathrm{EPQ} / \mathrm{EOQ}$ approach for perishable products. Authors previous work [6] also considered pricing in a specific structure or supply chain namely dual channel supply chain. In contorast to those aforementioned works, this research accommodates three period pricing on three echelon for fruit product handling. Common question will come up for proposed method whether dynamic pricing can help fruit supply chain players achieve better supply chain profit.

\section{Problem Modelling}

Conceptual model of problem is graphically presented below. There are three echelon of fruit supply chain players, which are supplier, wholesaler, and retailer.

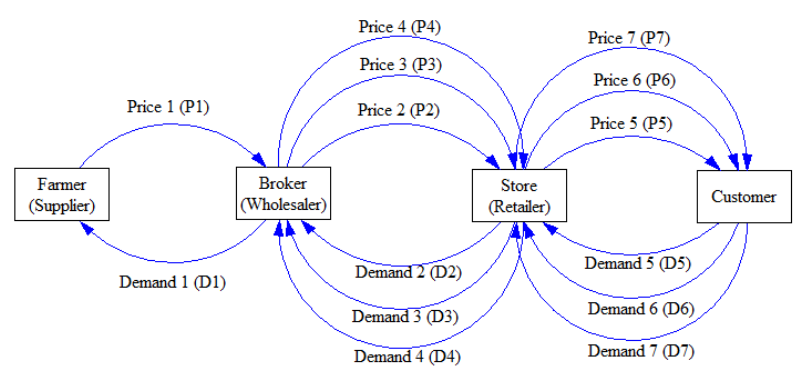

Fig. 1. Problem Mode

Based on fig. 1. Presented above, it is illustrated that there are different prices applied on wholesaler-retailer stage and retailer-customer stage. Price one (P1) is buyout price from wholesaler to retailer due to seasonal

\footnotetext{
* Corresponding author: erwin.widodo@ie.its.ac.id
} 
properties of fruit product. Price four (P2) and price seven (P5) are forward buying from each stage, while price three (P3) and price six (P6) are normal price. Last but not least price four (P4) and price seven (P7) are discounted or markdown price. There is pricing rule applied here follows this pattern $\mathrm{P}_{1} \leq \mathrm{P}_{2} \leq \mathrm{P}_{3} \geq \mathrm{P}_{4} \leq \mathrm{P}_{5} \leq \mathrm{P}_{6} \geq \mathrm{P}_{7}$, which is normal price is the highest price compare to forward and markdown prices.

\section{Mathematical Formulation}

Below, mathematical formulation for each demand will be elaborated. There is mathematical formulation represented demand one in tier one, which are farmerwholesaler relation.

$$
d_{1}=\alpha-\beta * p_{1}+\gamma *\left(c-p_{1}\right)
$$

Equation (1) explained that demand for the farmer is generated price one $\left(\mathrm{p}_{1}\right)$ and product cost $(\mathrm{c})$, where $\alpha$ represents base demand for whole supply chain. Price one $\left(\mathrm{p}_{1}\right)$ is price from farmer to wholesaler, which price is singular due to nature of harvesting period. In harvesting period, wholesaler mostly come to farmer's plant to buy goods in bulk amount.

While, demand formulation for tier two in fruit supply chain, which are wholesaler-retailer relationship. There are three formula represented each periodical demand gathered by price

$$
\begin{aligned}
& d_{2}=\alpha-\beta * p_{2}+\gamma *\left(p_{1}-p_{2}\right) \\
& d_{3}=\alpha-\beta * p_{3}+\gamma *\left(p_{2}-p_{3}\right) \\
& d_{4}=\alpha-\beta * p_{4}+\gamma *\left(p_{3}-p_{4}\right)
\end{aligned}
$$

From equation (2) to (4), known that there are four different prices involved on tier two. In demand two, demand is influenced by difference of price one, which is buying price of product to farmer and price two, which is first launched price to retailer called forward buying price. This price is higher or equal to price one, to generate profit for wholesaler.

Demand three explained that difference of price involved are price two and three. Price three indicates normal price after wholesaler release forward buying previously. While in demand four, price three and four are involved in the demand equation. Price four will be lower than price three due to beginning of deterioration rate. Hence, wholesaler release markdown price to trigger more demand for selling remaining unsold products.

While, demand formula for tier three in fruit supply chain, which are retailer-customer relationship. There are three formula represented each periodical demand gathered by price

$$
\begin{aligned}
& d_{5}=\alpha-\beta * p_{5}+\gamma *\left(p_{2}-p_{5}\right) \\
& d_{6}=\alpha-\beta * p_{6}+\gamma *\left(p_{5}-p_{6}\right) \\
& d_{7}=\alpha-\beta * p_{7}+\gamma *\left(p_{6}-p_{7}\right)
\end{aligned}
$$

Retailer to customer equations will be more or less the same with wholesaler to retailer equations. From equation
(5) to (7), known that there are four different prices involved on tier three. In demand five, demand is influenced by difference of price two, which is first launched price to retailer called forward buying price and price five that is first launched price to customer also called forward buying price. Condition explained above represent condition of demand five that occurred on forward buying period. Price five is higher or equal to price two to generate profit for retailer.

Demand six explained that difference of price involved are price five and six. It indicates normal price after releasing forward buying previously. While in demand seven, price six and seven are involved in the demand equation. This equation indicates markdown price after releasing normal price period previously. Price seven will be lower than price six and less than or equal to price five due to beginning of deterioration rate. Hence, retailer release markdown price to trigger more demand for selling remaining unsold products.

Following after demand mathematical formulation, supply chain profit mathematical formulation will be elaborated. There are three profit function on, which are farmer profit, wholesaler profit, and fruit supply chain profit.

$$
\begin{aligned}
\pi_{f}= & \left(P_{1}-C\right) * D_{1} \\
\pi_{w}= & \left(P_{2}-P_{1}\right) * D_{2}+\left(P_{3}-P_{1}\right) * D_{3}+\left(P_{4}-P_{1}\right) * \\
& D_{4} \\
\pi_{r}= & \left(P_{5}-P_{2}\right) * D_{5}+\left(P_{6}-P_{3}\right) * D_{6}+\left(P_{7}-P_{4}\right) * \\
& D_{7} \\
\pi_{s c}= & \left(P_{1}-C\right) * D_{1}+\left(P_{2}-C\right) * D_{2}+\left(P_{3}-C\right) * \\
& D_{3}+\left(P_{4}-C\right) * D_{4}+\left(P_{5}-C\right) * D_{5}+\left(P_{6}-\right. \\
& C) * D_{6}+\left(P_{7}-C\right) * D_{7}
\end{aligned}
$$

Equation (8) to (11) presented above are profit equation for each echelon and whole fruit supply chain profit. Equation (8) explained that profit of farmer is difference of unit cost and price from farmer to wholesaler $\left(\mathrm{P}_{1}\right)$ multiply demand from wholesaler to farmer $\left(\mathrm{D}_{1}\right)$. While in equation (9), profit of wholesaler is defined by sum of difference of forward buying, normal price, markdown price and buying price of product multiply by demand two to four. Following equation, equation (10) represents retailer profit. Profit of retailer is defined by sum of difference of forward buying, normal, and markdown prices of wholesaler and retailer multiply by demand five to seven. Last but not least, profit supply chain is defined by sum of difference of each price on each tier and cost unit multiply by its demand, that formulated on equation (11).

Besides equation declared above, constraint that worked on this problem need to be formulated. First constraint is nonlinear constraint. Nonlinear constraint is declared below

$p_{1} * p_{2} * p_{3} * p_{4} * p_{5} * p_{6} * p_{7} \geq$

$10,000,000,000,000,000,000,000,000,000$

$p_{1}{ }^{2}+p_{2}{ }^{2}+{p_{3}}^{2}+p_{4}{ }^{2}+p_{5}{ }^{2}+p_{6}{ }^{2}+p_{7}{ }^{2}=$ $1,600,000,000$ 
Non-linear equation above is making sure optimization will go well. Equation (12) represents condition that multiply of each price will be exceed 10,000 billion rupiahs. This condition will trigger the optimization to yield different prices by result. Hence, there may be price value $\mathrm{Rp} 4,000$ but later to be compensated by price value $\mathrm{Rp} 15,000$ in cases. Therefore, equation (13) complement previous equation by equalities condition. This equation will give boundary to price combination, that will make sure that sum of square of each prices will not exceed 1,6 million.

Next, constraint is linear constraint. There are two sets of linear constraint design for this optimization process. First linear constraint set is dedicated to wholesaler echelon. The linear constraint is presented as follows:

$$
\begin{aligned}
& p_{1}-p_{2} \leq 0 \\
& p_{2}-p_{3} \leq 0 \\
& -p_{3}+p_{4} \leq 0
\end{aligned}
$$

Equation (14) to (16) represents dynamic pricing rules. Equation (14) indicates condition that price one, which is buying price from farmer will be equal or lower than price two, which is forward buying price. Equation (150 indicates condition that price two, which is forward buying price will be lower or equal to price three, which is normal price. Equation (16) indicates condition that price three, which is normal price will be higher or equal to price four, which is markdown price.

Second linear constraint set is dedicated to retailer echelon. The linear constraint is presented as follows:

$p_{2}-p_{5} \leq 0$

$p_{3}-p_{6} \leq 0$

$p_{4}-p_{7} \leq 0$

Equation (17) to (19) presented above are represent dynamic pricing happened on retailer echelon. On equation (17), price five on retailer is forward buying price for customer that must be higher than or equal to price two, which is forward buying from wholesaler. Consequently, equation (18) and (19) indicate normal price and markdown price on retailer must be higher than or equal to normal price and markdown price on wholesaler stage.

$p_{5}-p_{6} \leq 0$

$-p_{6}+p_{7} \leq 0$

$-p_{5}+p_{7} \leq 0$

Equation (20) to (22) represents dynamic pricing rules. Equation (20) indicates condition that price five, which is forward buying price will be lower than or equal to price six, which is normal price. Equation (21) indicates condition that price six, which is normal price will be higher than or equal to price seven, which is markdown price. Equation (22) indicates condition that price five, which is forward buying price will be higher or equal to price seven, which is markdown price.
Following constraint is also linear constraint, but it express equality aspect of the problem. The equality constraint is declared below

$p_{1}+p_{2}+p_{3}+p_{4}+p_{5}+p_{6}+p_{7}=100,000$

Equality constraint above represented condition that sum of each prices is equal to 100,000 . This constraint triggers optimization process to yield unique price and sum of each prices do not excess that value.

Last step, all the equation is scripted into Matlab $\mathrm{R} 2010$ in order to optimize the problem. It is assisted by usage of FMINCON function to gather price should be made by each echelon in order to maximize the supply chain profit.

\section{Optimization Process}

Optimization Process begin with conducting numerical testing on three optimization scenarios. First scenario is using single prices on each echelon, which are IDR 10,000 as price one (P1), IDR 12,100, IDR 12,500, IDR 12,200 subsequently as price two (P2) to price four (P4), and IDR 15,000, IDR 15,900, IDR 15,200 subsequently as price five (P5) to price seven (P7). While, second and third scenario are dynamic prices which is automatically yield by optimization process. Results from Matlab are presented on figure two to four below.

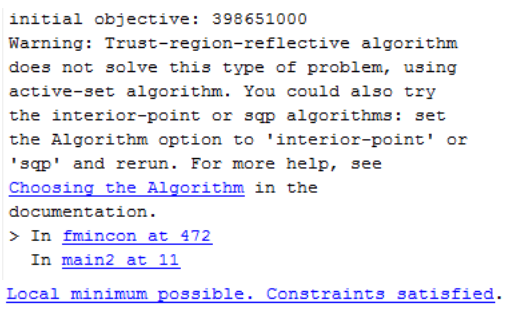

Fig.2. First Optimization Result

Based on optimization result presented above, known that optimization can answer question mentioned on introduction whether dynamic pricing could assist better profit fruit supply chain. Shown that final objective which is using dynamic pricing scheme yields higher profit compare to initial objective is using single price scheme, where initial objective value is 396 million rupiahs while using dynamic pricing is 553 million rupiahs. 


\section{Sensitivity Analysis}

There are two sensitivity done on this research. First sensitivity analysis on pricing section. While, second sensitivity analysis is on parameters involved in optimization. First sensitivity is conducting sensitivity on optimization process, which adds There is pricing rule applied on this sensitivity, which is common pricing rule mainly used by company from tourism area. Forward buying price, regularly on weekdays, is given lower price which is around $80 \%$ from weekend price, which is normal price. This pricing strategy is mainly applied by Bakery Company, where expiration does exist on bakery products. Pricing rule mathematical formulation and optimization results presented consecutively as follows

$p_{2}-0.8 * p_{3}=0$

$-0.5 * p_{3}+p_{4}=0$

Local minimum found that satisfies the constraints.

optimization completed because the objective function is non-decreasing in and constraints were satisfied to within the default value of the constraint tolerance.
and

<stopping criteria details>

Active inequalities (to within options. Tolcon $=1 e-006$ )

lower upper ineqlin inegnonith

1
4

$1.0 \mathrm{e}+004 *$

Columns 1 through 4

$\begin{array}{llll}0.8000 & 1.2800 & 1.6000 & 0.8000\end{array}$

Columns 5 through

$\begin{array}{lll}1.5934 & 2.3332 & 1.5934\end{array}$

final objective: 554081522.678

Fig.3. Second Optimization Result

Based on figure three presented above, final objective value is higher than preliminary optimization. Meaning that, this modified optimization is verified to seek better supply chain profit. Moreover, result gathered from this optimization is not possibilities of local optimum due to the objective function is non-decreasing on feasible directions. Wholesaler could apply dynamic pricing with scheme explained before, which was $80-50$ from Price three. While, retailer could apply dynamic pricing, where price five and price seven is on the same position in Rp 15,934 with $\mathrm{Rp} 23,332$ as normal price. Last but not least, farmer should reduce the initial price from $\mathrm{Rp} \mathrm{10,000} \mathrm{to}$ Rp 8,000. Therefore, it could become an aberration for farmer in spite of better profit for whole supply chain.

Second modified optimization try to solve first modified optimization and also attempt to achieve better supply chain profit. Following modification also using the pricing rule, but it is not scripted as equalization. Therefore, pricing scheme is scripted on non-equalization equation.

$$
\begin{aligned}
& p_{2}-0.8 * p_{3} \leq 0 \\
& -0.5 * p_{3}+p_{4} \leq 0 \\
& p_{5}-0.8 * p_{6} \leq 0 \\
& -0.5 * p_{6}+p_{7} \leq 0
\end{aligned}
$$

This modification is triggering the optimization to seek value of price which less than or equal to $0.8-0.5$ of price three and price six, where those two prices are normal price. Hence, decision can be made by echelons by reviewing dynamic pricing and impact to whole supply chain profit. Optimization result is presented as follows

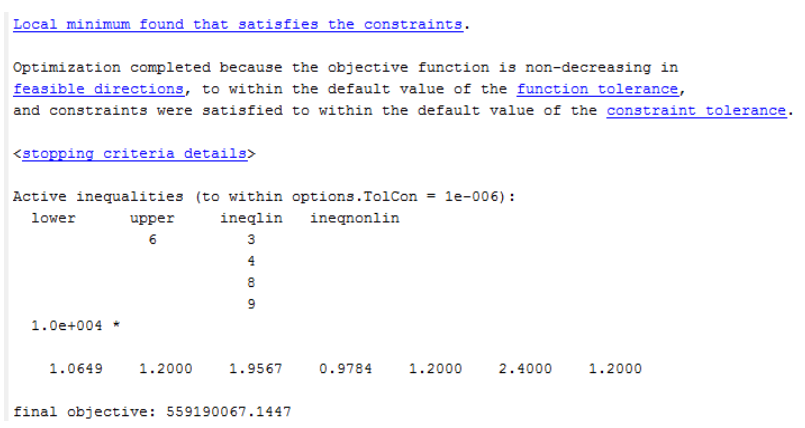

Fig.4. Second Optimization Result

Based on figure four presented above, final objective of second modified optimization value is higher than first optimization. Meaning that, this second modified optimization assist supply chain profit to better stage. Moreover, result gathered from this optimization is also local optimum that is fulfill all constraints due to the objective function is non-decreasing on feasible directions. By this optimization result, farmer is given bit higher price than initial price, in Rp 10,649 position. Wholesaler could apply dynamic pricing but not with exact $80-50$ from normal price, the dynamic pricing scheme will be Rp 12,00 for forward buying, Rp 19,567

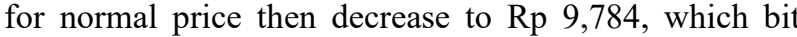
lower than price one, which is purchasing price from farmer. While, retailer place the same price for forward buying and markdown price on $\mathrm{Rp} 12,000$ position, with Rp 24,000 on normal price.

Following sensitivity analysis is conducting sensitivity for parameters involved on mathematical model. Based on formulation used on this model, there are three parameters which are $\alpha \beta$ and $\gamma$. Each parameters are increased and decreased by $20 \%$ to simulate their effect on fruit supply chain players profit. Below recap table of sensitivity analysis is presented.

Table 1. Parameters Sensitivity Recap

\begin{tabular}{|c|l|c|c|c|}
\hline \multirow{3}{*}{ Parameter } & Parameter & \multicolumn{3}{|c|}{ Profit Changes (\%) } \\
\cline { 2 - 5 } & Changes & Farmer & Wholesaler & Retailer \\
\hline \multirow{4}{*}{$\boldsymbol{\alpha}=\mathbf{5 0}$} & $-20 \%$ & -0.18 & -0.13 & -0.10 \\
\cline { 2 - 5 } & Threshold & 0 & 0 & 0 \\
\cline { 2 - 5 } & $+20 \%$ & $\mathbf{0 . 1 8}$ & 0.13 & 0.10 \\
\hline \multirow{5}{*}{$\boldsymbol{0}=\mathbf{0 . 5}$} & $-20 \%$ & 19.16 & $\mathbf{1 9 . 7 8}$ & $\mathbf{1 9 . 6 5}$ \\
\cline { 2 - 5 } & Threshold & 0 & 0 & 0 \\
\cline { 2 - 5 } & $+20 \%$ & -19.16 & -19.78 & -19.65 \\
\hline \multirow{5}{*}{$\gamma=\mathbf{0 . 0 5}$} & $-20 \%$ & $\mathbf{1 . 0 2}$ & $\mathbf{0 . 3 5}$ & $\mathbf{0 . 4 5}$ \\
\cline { 2 - 5 } & Threshold & 0 & 0 & 0 \\
\cline { 2 - 5 } & $+20 \%$ & -1.02 & -0.35 & -0.45 \\
\hline
\end{tabular}


Based on table one presented above, each parameter has different effect to FSC players' profitability. Higher alpha will beneficial to farmer represented by higher profit changes to compare to other players. While, beta parameter that represents latest price review sensitivity constant, gives more profitability tendency to wholesaler. Nevertheless, beta can also useful to retailer due to higher profit changes when lower beta is set. Last but not least, lower gamma will give higher profitability tendency to farmer. While, changes of beta gives lower impact for wholesaler and retailer compare to farmer. This condition can be approached by anomaly effect of gamma to demand that will be comprehensively elaborated on section six.

\section{Discussion \& Findings}

Mostly, Retailer Company on Indonesia offer banana on single price, for certain package of banana (no scaling process), for all selling period. Fruit like banana, has lifetime period before it ends as deteriorated product. Hence, retailer should be smart to push selling of deteriorative product such as fruit to prevent it is unsold, which can be overcame by applying forward buying. In example, based on figure four, retailer can offer $\mathrm{Rp}$ 12,000 per $\mathrm{kg}$ of banana when banana still on raw condition. Raw condition can be determined by color of banana skin and gentleness of banana fruit body. This price push demand into earlier period, therefore it can be used to prevent risk of unsold product. Then, retailer could begin mark up the price when there is indication of banana soon to be on well-consumed period. Again, based on figure four retailer should offer Rp 24,000 per $\mathrm{kg}$ of banana. This price still way too low from banana price on convenience store that observed by author. It indicates that retailer can play price since market acceptance level price still higher than threshold price. Last but not least, when fruits is indicating over well-consumed period, that can be determined by changes of banana fruit skin and gentleness of its fruit body as well, retailer could give lower price that commonly half price than normal price or just cost of goods sold price. This step also prevent risk of unsold product like forward buying price.

Besides prices, profit value is also need to be discussed. Based on optimization process known that supply chain profit growing better. Thing need to be discussed is prices involved on each profit. On first modified optimization model, FSC profit can be reach value $\mathrm{Rp} 554$ million rupiahs, with pricing rules $80-50 \%$ on wholesaler stage, and decreasing farmer price $20 \%$ lower than initial price. While second modified optimization model could lead to better FSC profit in value $\mathrm{Rp} 559$ million rupiahs. On this scheme, there is no $80 \%-50 \%$ pricing rules, but markdown price of wholesaler bit lower than buying price from farmer. Several consideration need to be elaborated here that is whatever the FSC profit considered by its player the decision still depend on the market. Meaning that, FSC players could take first modified optimization model, where farmer regain the price from $\mathrm{Rp} 8,000$ to $\mathrm{Rp} 10,000$ as long as wholesaler still willing to buy it and wholesaler market (retailer) tend to purchase markup price from wholesaler. Consequently, FSC players could take second modified optimization where it yields better FSC profit. Wholesaler also could regain their markdown price as long as retailer still willing to buy it and retailer market (customer) tend to purchase it. There are several thing can be concluded from here, which are

1. Dynamic pricing condition and its profit can be achieved by collaboration within FSC players, which its market need to be observed due to their obligation to adjust optimization done by FSC players

2. Dynamic pricing is worth to try due to this scheme can yield better whole supply chain profit. Besides, dynamic pricing is closer to the reality, where customer tend to purchase fruit in good condition. Hence, retailer could offer markdown price for fruit which start to deteriorate to prevent unsold product risks. Moreover, retailer also need to push forward buying with also offer price lower than normal price to prevent abundant amount of fruit start to deteriorate in markdown price selling period.

Second discussion is about parameters sensitivity analysis result. Alpha ( $c$ ) has more positive impact to farmer profit reflected by higher profit changes compare to wholesaler and retailer. It can be elaborated that farmer uses a single price to sell product to wholesaler. Hence, higher alpha, which is higher base demand placed by wholesaler to farmer, will raise the profit for farmer. Nevertheless, in real condition there are several consideration, which are nature of product and also market condition. Fruit product has nature to become deteriorative product in the end. Moreover, market condition can be so fluctuated. In previous chapter dynamic pricing assist to demand pushing, in the other side macro-economic condition that cannot be controlled. Commonly, fruit is bought in $50 \mathrm{~kg}$ amount from farmer on harvesting period which was set as initial base demand that used on the optimization. Based on consideration explained above, FSC players should consider certain number as a base demand to achieve targeted FSC profit.

Next parameter is beta. Based on table one from previous section presents that lower beta will give higher profit changes to wholesaler and retailer that come in second than farmer. Beta is represented latest price sensitivity, which is more related to wholesaler and retailer due to dynamic pricing scheme application. On dynamic pricing, there are several prices which can be lower or higher to one another. Declaring latest price has an impact to customer perception whether latest price is affordable or not. Beta parameter try to capture customer sensitivity to latest price. From previous paper, which is Maiti \& Giri [1], valued default beta in 0.5. It insisted that customer sensitivity to latest price has great portion to effect demand for FSC players. Less than 0.5 value, demand will be higher and so does profit. In the other hand, the higher 0.5 value of beta, which is customer very sensitive to latest price declared or released by FSC players.

Condition explained above reflects real market condition. Higher latest price, may decrease customer willingness to pay. While, on lower latest price, it may increase customer willingness to pay. Nevertheless, FSC 
players applies higher price under condition of good condition fruit, which is period that has been waiting for by customer. While lower price is applied on before and after-good condition of fruit. This mechanism is compensated each other. Customer is given few options to buy before or after-good condition of fruit with lower price or good condition of fruit with higher price. Hence, FSC players should take an option to offer small gap between normal price and under normal price, remind that purpose of lowering the price to push demand to forward buying and prevent outdated fruits.

Last but not least is gamma. Gamma has unique impact on optimization. Based on Figure 6.2, gamma has positive impact to yield demand to FSC players. Nevertheless, table one also shows that lower gamma can give positive impact to higher profit changes to FSC players, especially farmer.

$d_{n}=\alpha-\beta * p_{n}+\gamma *\left(c-p_{n}\right)$

In farmer stage, this redundancy happened due to different of price offered to wholesaler. Gamma represents price correction from earlier price to latest price operate on its system. In farmer, due to application of single price, selling price to wholesaler directly minus by cost of product. Since selling price higher than cost of product, this price correction will increase the profitability where its price correction amplified by gamma.

In wholesaler and retailer stage, this redundancy happened due to application of dynamic pricing scheme. In example, on retailer stage different price of forward buying price to normal price, will be noted as negative reviewed by customer due to higher latest price than previous price. In the other hand, changes of normal price to markdown price will be noted as positive reviewed by customer due to decreasing price from previous prices. Gamma will amplify both of negative and positive review. In this dynamic pricing scheme, there is four negative review happened, two on each wholesaler and retailer, but only two positive review happened, one on each wholesaler and retailer. It can be concluded that gamma is following dynamic pricing scheme, which can be amplified both of negative or positive review of prices from customer.

One consideration need to be discussed, whether beta and gamma that captured as most sensitive parameter. From recent optimization, higher constant of beta make it as most sensitives compare to lower constant of gamma. Nevertheless, further market research need to be done to select which of those two parameters is the most influential for fruit supply chain. It can be indicated that on FSC, reviewing of price changes due to nature of product, can be considered as more sensitive compare to reviewing of latest price. Hence, higher constant can be given to gamma than beta.

\section{Conclusion \& Future Research Suggestion}

From chapter five and six, several ideas can be underlined to be served as conclusion. Several conclusion are presented as follows

1. A set of mathematical model has been proposed to address dynamic pricing for FSC players to achieve better profitability. Dynamic pricing is urgent to be done due to nature of fruit product, where deteriorative period does exist. Hence, in order to avoid unsold product due to became deteriorated, dynamic pricing could become solution to push demand in several selling period, which are forward buying, normal price, and markdown price period compare to single price for all selling period, that is already proved by optimization.

2. Optimization parameters has their own effect on FSC profit. Alpha which is base demand could trigger higher demand for FSC players. Nevertheless, amount of base demand need to be considered due to nature of product and market condition. While, beta give negative impact on FSC profit, where it represent customer sensitivity to latest price, which is also considered as most sensitive parameter on optimization process. In addition, gamma could give both positive and negative impact depend on dynamic pricing scheme, which is could be considered as candidate to become most sensitive parameter on FSC.

3. FSC players could gather better profit supply chain, which affected by dynamic of demand due to dynamic pricing. Demand function reflect that customer preference to buy is more affected to latest price ( $\beta$ ) than difference of latest price compare to previous price $(\gamma)$. Hence, FSC players should prepare marketing technique for releasing latest price to their customer.

There are several suggestion that can be considered for future research, that is judgement or rules that apply for beta and gamma in order to capture price resulted from optimization process. Hence, constant of beta and gamma will follow price set by FSC players that represent customer or market sensitivity. Moreover, more consideration on mathematical formulation and model, in example inventory consideration and dynamic of base demand to enrich optimization result that could assist FSC players better. Last but not least, this research can be conducted by Graduate Grant of ITS Surabaya support.

\section{References}

1. Soto-silva, W.E. et al., 2015. Operational research models applied to the fresh fruit supply chain. European Journal of Operational Research, 0, pp.111.

2. FAO. 2014. Crops Statistics. Available at: http://www.fao.org/faostat/en/\#data/QC (Accesed : 14 August 2017).

3. Chen, W., Li, J. \& Jin, X., 2016. The replenishment policy of agri-products with stochastic demand in 
integrated agricultural supply chains. Expert Systems with Applications, 48, pp.55-66.

4. Maiti, T. \& Giri, B.C., 2016. Two-period pricing and decision strategies in a two-echelon supply chain under price-dependent demand. , 0, pp.1-20.

5. Fauza, G. \& Lee, S., 2015. A Vendor-Buyer Inventory Model for Food Products Based On Shelf-Life Pricing. , 8(2), pp.67-73.

6. Widodo, E., Takahashi, K., Morikawa, K., Pujawan, I.N. and Santosa, B. 'Managing sales return in dual sales channel: an analysis of primary versus secondary resale strategies', Int. J. Industrial and Systems Engineering, Vol. 15, No. 2, pp. 119-151 